\title{
ELECTROENCEPHALOGRAPHIC CHANGES AFTER ONE NIGHT OF SLEEP DEPRIVATION
}

\author{
Camila Ferreira ${ }^{1}$, Andréa Deslandes ${ }^{1}$, Helena Moraes ${ }^{1}$, Maurício Cagy², \\ Fernando Pompeu ${ }^{3}$, Luis Fernando Basile ${ }^{4}$, Roberto Piedade ${ }^{5}$, Pedro Ribeiro 6
}

\begin{abstract}
Total or partial sleep deprivation (SD) causes degrading effects on different cognitive and psychomotor functions that might be related to electrophysiological changes frequently observed. In the present study, we investigated the effects of one night of sleep deprivation on waking EEG. Experimental protocol consisted of recording electroencephalographic data from eleven healthy young subjects before (baseline) and after (time 2) one night of sleep deprivation. A natural log transformation was carried out and showed a significant increase in theta T6 $(p=0.041), O 2(p=0.018)$ and OZ $(p=0.028) ;$ and delta T6 $(p=0.043)$ relative power; and a decrease in alpha Fp1 $(p=0.040), F 3(p=0.013), F p 2(p=0.033), T 4(p=0.050)$, T6 $(p=0.018), O 2(p=0.011)$ and $\mathrm{Oz}(p=0.025)$ and beta $(p=0.022)$ absolute power. These outcomes show that the EEG power spectra, after sleep deprivation, exhibit site-specific diff e rences in particular fre qu e $n$ cy bands and corroborate for the premise of local aspects of brain adaptation after sleep deprivation, rather than global.
\end{abstract}

KEY WORDS: sleep deprivation, qEEG, power spectral analysis, cortical activity.

\begin{abstract}
Respostas eletrencefalográficas após uma noite de privação de sono
RESUMO - Privação total ou parcial de sono causa efeitos deletérios em diferentes funções cognitivas e psicomotoras, que podem estar relacionados às mudanças eletrofísiológicas frequentemente observadas. No p resente estudo, investigou-se os efeitos de uma noite de privação de sono nas respostas eletrencefalográficas de repouso. O protocolo experimental consistiu na coleta e gravação dos dados do qEEG de onze sujeitos jovens e saudáveis antes (momento baseline) e após (momento 2) uma noite de privação de sono. Todos os dados sofreram transformação logarítmica, que evidenciou um aumento significativo nas potências relativas de teta T6 $(p=0,041), 02(p=0,018)$ e OZ $(p=0,028)$; e delta T6 $(p=0,043)$. As bandas de freqüência mais rápidas alfa Fp1 $(p=0,040), F 3(p=0,013), F p 2(p=0,033), T 4(p=0,050), T 6(p=0,018), 02(p=0,011)$, $\mathrm{Oz}(p=0,025)$ e beta $(p=0,022)$ apresentaram reduções significativas na potência absoluta. Os resultados demonstram que o espectro de potência exibe diferenças específicas em freqüências de bandas diferentes, e corroboram para a premissa de que o cére b ro, após privação ou perda de sono, promove ajustes e adaptações locais, ao invés de globais.
\end{abstract}

PALAVRAS-CHAVE: privação de sono, qEEG, análise do espectro de potência, atividade cortical.

Sleep is essential to proper brain functioning and the lack of it results in perf o rmance impairment during everyday cognitive tasks ${ }^{1-7}$ Sleep deprivation (SD) seems to exert local and specific effects on the brain, rather than global. Recent electroencephalographic and neuroimaging studies revealed that the pre$f$ rontal cortex (PFC) is more responsive to sleep deprivation then other brain areas ${ }^{2,8-12}$, which is expected since the frontal region has a greater restorative need than other areas of the brain. In fact, during non-REM sleep, in the rebound sleep after SD, the increase in delta-wave frequency $(1-4 \mathrm{~Hz}$, slow wave activity related to deep sleep) occurs first in the PFC and later on other areas of the cortex ${ }^{13,14}$, suggesting the importance of the initial re covery in this region. A few recent studies ${ }^{2,3,8}$ pe rceived that, contrary to all expectations, after sleep deprivation, the PFC was significantly more activated during a diff e rent tasks

\footnotetext{
'Laboratório de Mapeamento Cerebral e Integração Sensório-Motora, Instituto de Psiquiatria (IPUB), Universidade Federal do Rio de Janeiro, Brasil (UFRJ); ${ }^{2}$ COPPE, Universidade Federal do Rio de Janeiro, Brasil (UFRJ); ${ }^{3}$ Departamento de Biociências e Atividade Física, Escola de Educação Física e Desportos (EEFD), UFRJ; ' Laboratório de Neurociências (LIM-27) Faculdade de Medicina da Universidade de São Paulo, SP Brasil; ${ }^{5}$ Co o rdenador Laboratório de Mapeamento Cerebral e Integração Sensório-Motora, IPUB, UFRJ; ${ }^{6}$ Laboratório de Mapeamento Cerebral e Integração Sensório-Motora, IPUB-UFRJ, Professor Pesquisador UFRJ/IPUB e Universidade Castelo Branco (PROCIMH-UCB).
}

Received 26 September 2005, received in final form 16 January 2006. Accepted 18 February 2006.

Dra. Camila Ferreira - Rua Delfina 47 / 104 - 20511-270 Rio de Janeiro RJ - Brasil. E-mail: camilaferreira@libero.it 
supporting the hypothesis of local dynamic compensatory changes in the brain electrical activity after sleep deprivation.

Studies concerning quantitative electro encephalography (qEEG) are still contradictory and have divergent results. The majority of EEG investigations reports the effects of SD on the rebound sleep, and considering the extended literature on sleep, very few studies have tried to observe electrophysiological changes during prolonged wakefulness ${ }^{15-19}$. EEG is a useful and sensitive tool related to cognitive processes of vigilance and, therefore, it can be used to understand the consequences of sleep loss in the brain electrical activity and functional organization while individuals are still awake. It has been demonstrated by EEG spectral analysis that SD alters cortical activity during prolonged wakefulness ${ }^{15-19}$. Spectral power analysis ${ }^{17}$ has revealed an increase in the absolute power of theta, alpha and beta bands after sleep deprivation; but the same authors ${ }^{18}$ obsened later a reduction in alpha, although theta remained increased. Some studies also reported a reduction in the absolute power of all bands, except for delta, and a significant increase in theta absolute power in frontal and temporal areas ${ }^{11}$. Corsi-Cabrera ${ }^{6}$ observed an increase in alpha and beta absolute power in the occipital area. As noted, studies involving EEG are still very much at odds, probably due to different methodologies and individual variability.

Therefore, the aim of this study was to observe and attempt to elucidate the electrophysiological changes followed by one night of sleep deprivation.

\section{METHOD}

Subjects - The sample consisted of 11 individuals, 4 males and 7 females, with ages varying between 21 and 40 years (30.8 \pm 6.0 years). All subjects were healthy, right-handed, non-smokers, and were not making use of any psychoactive or psychotropic substance at the time of the test. To ensure that subjects did not present any impairment of their physical and mental health, a questionnaire was applied. The questionnaire also aimed at identifying food intake, body temperature, fatigue, and drugs use, among others. Subjects were not allowed to consume any alcoholic beverages or caffeine. The Edinburgh inventory was used to assess laterality and exclude left-handed individuals from the experiment. All subjects signed a consent form, where the experimental condition was thoroughly described. The Psychiatric Institute's Ethics Committee approved the experiment.

Study and procedures-Electrophysiological recording occuned in two diff e rent times: pre- and post-sleep deprivation (which itself took all night long). Subjects arrived at the laboratory by 8:00 p.m. and performed the first qEEG recording (time 1- baseline). During the whole period of sleep deprivation (night), volunteers played games, watched videos and carried out recreational activities, and were also fed each three or four hours. Two experimenters who were required to ensure continuous wakefulness of the subjects monitored sleep deprivation continuously. Subjects abstained from smoking or drinking xanthine-containing beverages (coffee, tea, cola or soft drinks). No concurrent tre atment was allowed during the study. At 7:00 a.m. (time 2after sleep deprivation) of the subsequent morning, all subjects repeated the same identical q EEG recording.

Electroencephalogram recording - The study design respected the International Pharmaco-EEG group guidelines. Subjects were seated comfortably in a sound-lightattenuated room, while EEG was collected from 20 monopolar derivations for five minutes (eyes closed, alert but resting). Data were collected with eyes closed in order to observe the cortex electrical activity without any external stimuli, minimizing possible visual artifacts. Electrodes were positioned according to the International 10/20 System (referred to linked earlobes with ground at FPZ). All electrode impedances were kept below $5 \mathrm{k} \Omega$. The signal was amplified with a gain of 22,000, analogical ly filtered between $0.01 \mathrm{~Hz}$ (high-pass) and $100 \mathrm{~Hz}$ (low-pass), and sampled at $240 \mathrm{~Hz}$ using a Braintech-3000 ${ }^{\circledR}$ (EMSA-Medical Instruments, Rio de Janeiro, RJ, Brazil) EEG acquisition system. The EEG was recorded by means of the software ERP Acquisition (Delphi $5.0^{\circledR}$, Borland-Inprise), developed at the Brain Mapping and Sensorimotor Integration Lab, employing the following digital filters: notch $(60 \mathrm{~Hz})$, high-pass of $0.3 \mathrm{~Hz}$ and low-pass of $25 \mathrm{~Hz}$. Visual inspection was employed for detection and elimination of artifacts. Eye-movement (EOG) artifact was monitored with a bipolar electrode montage using two 9-mm-diameter electrodes attached superior to and on the external cantus of the right eye.

Data analysis - At least two minutes of artifact-free data we re extracted from the EEG's total record for quantitative analysis. A Matlab $5.3^{\circledR}$ (The Mathworks Inc., Massachusetts, USA) routine was implemented to perform a spectral analysis. For each of the 20-monopolar derivations, absolute and relative powers $(\mu \mathrm{V} 2)$ were computed for the delta $(1.0-3.5 \mathrm{~Hz})$, theta $(4.0-7.5 \mathrm{~Hz})$, alpha $(8.0-12.0 \mathrm{~Hz})$, and beta $(13-25 \mathrm{~Hz})$ frequency bands.

Statistical analysis - Data were expressed as mean \pm s.d. The statistical software SPSS for Windows was used for all data analysis. Preliminarydescriptive examinations revealed that none of the evaluated EEG indexes had a normal distribution. To obtain a better approximation of a normal distribution, data from the power spectra were submitted to a log transformation (LOG 10, log absolute power). Significance levels were set at $p \leq 0.05$.

\section{RESULTS}

One night of sleep deprivation caused a significant power decrease in the frontal, temporal and 


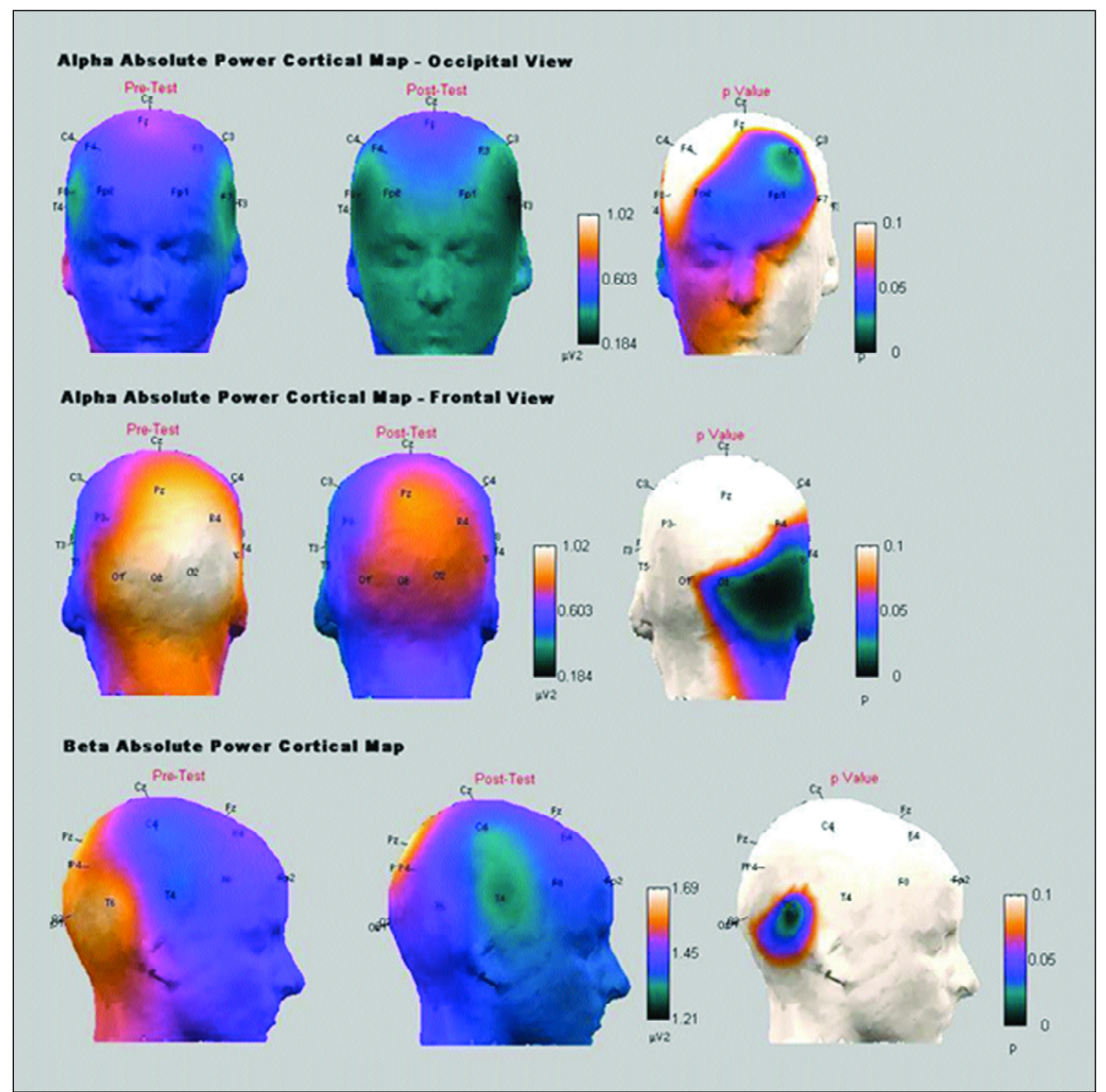

Fig 1. Alpha absolute power cortical map showing both frontal and occipital views. One night of sleep deprivation caused a significant power decrease in frontal, temporal and occipital areas in this frequency band. Electrodes Fp1 $(p=0.040), F 3(p=0.013), F p 2(p=0.033), T 4(p=0.050), T 6(p=0.018), O 2(p=0.011)$ and $\mathrm{Oz}(p=0.025)$ illustrate remark able reductions. The beta absolute power cortical map also presents a significant power decrease in temporal region, specially, in the T6 electrode $(p=0.022)$ after one night of sleep deprivation $\left({ }^{*} p \leq 0.05\right)$.

occipital areas of the alpha frequency band, in the following electrodes: Fp1 ( $p=0.040), F 3(p=0.013)$, Fp2 $(p=0.033), T 4(p=0.050), T 6(p=0.018), 02(p=0.011)$ and $\mathrm{Oz}(\mathrm{p}=0.025)$. The beta frequency band also experienced power reduction in the temporal area $(p=$ $0.022)$. Temporal delta $(p=0.043)$ and temporal-occipital theta T6 $(p=0.041), 02(p=0.018)$ and OZ $(p=$ 0.028 ), instead, exhibited power increases after SD. Cortical maps represented by Figures 1 and 2 represent the significant electrophysiological results found in the present study

\section{DISCUSSION}

The real implication of sleep is still not entirely clear and there fore the effects of sleep deprivation or sleep loss also cannot be fully understood yet. The present study demonstrated that one night of sleep deprivation caused specific electrophysiological changes, such as relative delta and theta power increase, and absolute alpha and beta power reduction. Our findings are in agreement with previous results $5,6,11,18,20$ which observed the same alterations in the brain electrical activity. Electrophysiological alterations such as 


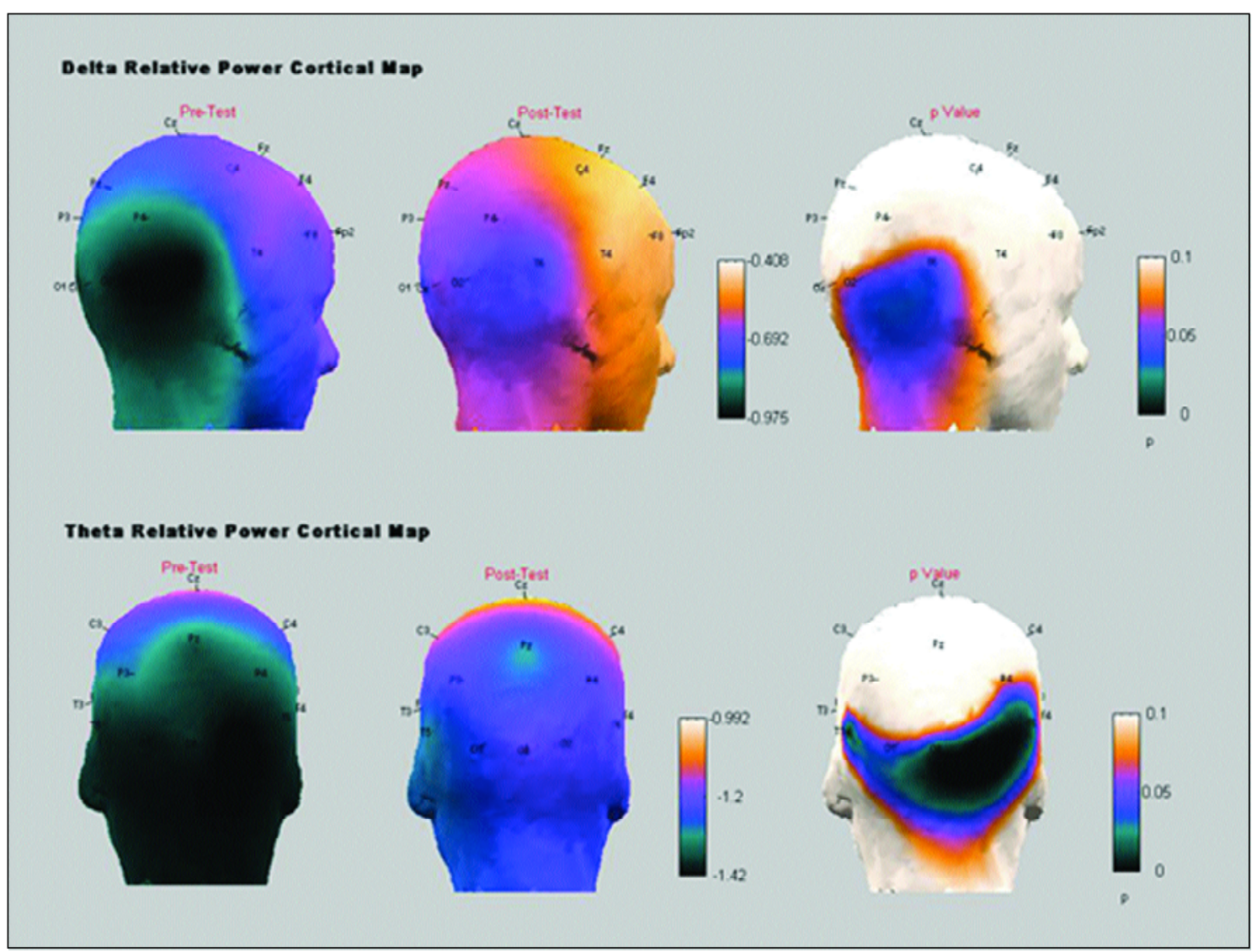

Fig 2. Theta relative power cortical map. The occipital view of this frequency band exhibits the power increase obsened after one night of sleep deprivation in the following electrodes: T6 ( $p=0.041), 02(p=0.018)$, and Oz $(p=$ 0.028 ). An also significant power augmentation was observed in the delta band. The delta relative power cortical map, in particular electrode T6 $(p=0.043)$ displays the power changes observed after one night of sleep deprivation $\left({ }^{*} p \leq 0.05\right)$.

an increase in theta relative power in occipital and temporal areas, and in delta relative power in temporal regions were expected since the subjects were feeling each time sleepier and less alert (no scales were used, subjects simply were frequently asked about their subjective feelings of sleepiness throughout the whole experiment). It is clear that the amount of theta becomes more pronounced as the period of continuous wakefulness prog resses; despite the fact that cognitive workload (e.g., task demands) requirements did not change. Increased theta activity is found ${ }^{21}$ to correlate with increased workload, as well as increased fatigue. However, the widespread augmentation 22 of theta activity has more traditionally been associated with impaired alertness. In addition, these generalized low-frequency EEG patterns have been associated ${ }^{23}$ with decrements in vigilance tasks. Although changes in EEG theta activity can be interpreted as something other than an indication of an individual state of alertness (for example, a correlation has been observed between theta activity and cognitive workload), experimental evidences have shown that theta is in fact a trust worthy indicator of great central nervous system inhibition associated ${ }^{24}$ with low arousal and diminished information processing. Based on the present knowledge about sleep loss and sleep deprivation, physiological arousal and perf o rmance; both EEG and behavioral findings obsened in the present study are coherent with the lite ratu re. In sleep-deprivation paradigms, it has been well established $^{22}$ that prolonged wakefulness is accompanied by systematic power increases in theta activity. Contextual stimulation is known to attenuate $^{25}$ the effects of sleep deprivation, and thus, the impact of sleepiness on alertness may have been reduced modestly preventing greater delta power inc rease (e.g., frank sleep episodes), while still not altogether eliminating its appearance in slow-wave EEG. This could help explain why delta power did not show a large increase all over the scalp, but instead, was limited to the temporal area (T6 electrode). 
Alpha power during waking EEG is also of part icular interest for the researh on sleep deprivation, sleep loss and sleepiness. Throughout active wakefulness (eyes open), alpha power is usually low, but if the individual is severely fatigued ${ }^{26}$, it might increase. However, in resting conditions (eyes closed), alpha power is high also when the subject is fully rested. Several studies observed that during the transition f rom resting conditions with eyes closed to sleeping, a gradual reduction in alpha power occurs, all together with an increase in theta power ${ }^{26-28}$. So, if the subjects experience progressively higher sleepiness sensation as the hours of wakefulness proceed, the observed reduction in alpha power is expected. Consequently, reduced alpha power during waking periods may indicate a high motivation for sleeping; indeed it has been already found ${ }^{28}$ that subjective sleepiness during sleeplessness periods correlates negatively with alpha power and positively with theta power during the waking EEG after sleep deprivation. Also, the early stages of drowsiness, experienced he re by the subjects after prolonged wakefulness, a re characterized by what it's called an "alpha power dropout". The trains of alpha waves become less and less continuous and the last alpha fragments give place to a low voltage pattern of mixed slow frequencies (e.g., delta and theta). Alpha activity counteracts with theta activity; i.e., a slowing of posterior alpha is substituted gradually by the posterior theta activity (and delta), as the motivation to sleep in$c$ reases. These adjustments in the spectrum towards slower frequency bands were better observed here by the temporal activity changes (T6 electrode), since we found an alpha and beta power reduction and an accordingly a theta and delta power increase in this area. Since these changes are very common in the elderly ${ }^{29}$ or in patients suffering from dementia, we can only speculate about the substantial correlation between these EEG abnormalities observed after sleep deprivation (spectrum shift to slower frequencies) and a cognitive deficit.

Some investigators also observed that the alpha power reduction after sleep deprivation may be related to a reduction of activation in sub-cortical brain structures with general cortical activation properties, e.g., brain stem, midbrain, hypothalamus and other parts of the limbic system, since these structures show a positive correlation between regional cerebral blood flow and cortical alpha power ${ }^{30}$ in resting conditions. Moreover, the positive correlation between beta absolute power increase (e.g., temporal region) and the hours of prolonged wakefulness might be interpreted as an index of effortand temporary acti- vation. A speculative interpretation may be that the observed beta power increase reflects processes underlying an increasing effort to maintain wakefulness, i.e., the motivation to stay awake, that coincides ${ }^{16}$ with an increased feeling of sleepiness.

In conclusion, the present study demonstrated that one night of sleep deprivation was associated with: (1) increased resting EEG theta and delta relative power with a specific occipital/temporal focus, (2) decreased resting EEG beta absolute power in the temporal area and (3) decreased resting EEG alpha absolute power centered in the frontal, temporal and occipital areas of the cortex. The electrophysiological adjustments of the brain after sleep deprivation or sleep loss are still not entirely clear, but it is highly plausible to be local, rather than global, processes. Future rese arch is still necessary to replicate these findings and maybe correlate qEEG changes with behavioral responses. The processes underlying these electroencephalographic changes are connected to each other and might reflect the performance impairments that commonly accompany the loss or deprivation of sleep, leading us to our choice to go to sleep.

\section{REFERENCES}

1. Franken P, Dijk DJ, Tobler I, Borbely AA. Sleep deprivation in rats: e ffects on EEG power spectra, vigilance states, and cortical temperature. Am J Physiol 1991;261:198-208.

2. Drummond SP, Brown GG. The effects of total sleep deprivation on ce rebral responses to cognitive performance. Neuropsychopharmacology 2001;25:68-73.

3. D rummond SP, Gillin JC, Brown GG. Increased cerebral response during a divided attention task following sleep deprivation. J Sleep Res 2001;10:85-92.

4. Drummond SP, Brown GG, Gillin JC, Stricker JL, Wong EC, Buxton RB. Altered brain response to verbal learning following sleep deprivation. Nature 2000;10:655-657.

5. Patat A, Rosenzweig P, Enslen M, et al. Effects of a new slow release formulation of caffeine on EEG, psychomotor and cognitive functions in sleep-deprived subjects. Hum Psychopharmacol 2000;15:153-170.

6. Corsi-Cabrera M, Arce C, Ramos J, Lorenzo I, Guevara MA. Time course of reaction time and EEG while performing a vigilance task during total sleep deprivation. Sleep 1996;19:563-569.

7. Batejat D, Lagarde D. Circadian rhythm and sleep deprivation: effects on psychomotor performance. Med Sci Res 1992; 20:167-168.

8. Chee MW, Choo WC. Functional imaging of working memory after 24 $\mathrm{hr}$ of total sleep deprivation. J Neurosci 2004;24:4560-4567.

9. Cajochen C, Foy R, Dijk DJ. Frontal predominance of a relative increase in sleep delta and theta EEG activity after sleep loss in humans. Sleep Res Online 1999;2:65-69.

10. Schwierin B, Achermann P, Deboer T, Oleksenko A, Borbely AA, Tobler I. Regional differences in the dynamics of the cortical EEG in the rat after sleep deprivation. Clin Neurophysiol 1999;110:869-875.

11. F o rest $G$, Godbout R. Effects of sleep deprivation on performance and EEG spectral analysis in young adults. Brain Cogn 2000;43:195-200.

12. Jones K, Harrison Y. Frontal lobe function, sleep loss and fragmented sleep. Sleep Med Rev 2001;5:463-475.

13. Maquet $P$. The role of sleep in learning and memory. Science 2001;2; 294:1048-1052.

14. Werth E, Achermann P, Borbely AA. Brain topography of the human sleep EEG: antero-posterior shifts of spectral power. Neuroreport 1996; 20;8:123-127. 
15. Garcia-Garcia F, Beltran-Parrazal L, Jimenez-Anguiano A, Vega-Gonzalez A, Dru cker-Colin R Manipulations during forced wakefulness have diff e rential impact on sleep architecture, EEG power spectrum, and Fos induction. Brain Res Bull 1998;47:317-324.

16. Strijkstra AM, Beersma DGM, Drayer B, Halbesma N, Dann S. Subjective sleepiness correlates negatively with global alpha $(8-12 \mathrm{~Hz})$ and positively with central frontla theta $(4-8 \mathrm{~Hz})$ frequencies in the human awake electroencephalogram. Neurosci Letters 2003;340:17-20.

17. Corsi-Cabrera M, Ramos J, A rce C, Guevara MA, Ponce-de-Leon M, Lorenzo I. Changes in the waking EEG as a consequence of sleep and sleep deprivation. Sleep 1992;15:550-555.

18. Corsi-Cabrera M, Sanchéz AI, Del-Rio-Portilla Y, Villanueva Y, PérezGarcí. Effect of $38 \mathrm{~h}$ of sleep deprivation on the waking EEG in womem: sex differences. Internat J Psychophysiol 2003;50:213-224.

19. Ugalde E, Corsi-Cabrera M, Juarez J, Ramos J, Arce C. Waking electroencephalogram activity as a consequence of sleep and total sleep deprivation in the rat. Sleep 1994;17:226-230.

20. Kim H, Guilleminault C, Hong S, Kim D, Kim S, Go H, Lee S. Pattern analysis of sleep-deprived human EEG. J Sleep Res 2001;10:193-201.

21. Hankins TC, Wilson GF. A comparison of heart rate, eye activity, EEG and subjective measures of pilot mental workload during flight. Aviat Space Environ Med 1998;69:360-367.

22. Caldwell JA, Prazinko BF, Hall KK. The effects of body posture on resting electroencephalographic activity in sleep-deprived subjects. Clin Neurophysiol 2000;111:464-470.
23. Belyavin A, Wright NA. Changes in electrical activity of the brain with vigilance. Electroencephalogr Clin Neurophysiol 1987;66:137-144.

24. Ray WJ. The electrocortical system. In Cacioppo JT, Tassinary, LG (eds). Principles of psychophysiology. New York: Cambridge University Press, 1990:382-412.

25. Dijkman M, Sachs N, Levine E, et al. Effects of reduced stimulation on ne u robehavioral alertness depend on circadian phase during human sleep deprivation. Sleep Res 1997;26:265-272.

26. Klimesch W. EEG alpha and theta oscillations reflect cognitive and memory performance: a review and analysis. Brain Res Brain Res Rev 1999; 29:169-195.

27. Tanaka H, Hayashi M, Hori T. Topographical characteristics and principal component structure of the hypnagogic EEG. Sleep 1997;20:523534.

28. Dijk DJ, Czeisler CA. Contribution of the circadian pacemaker and the sleep homeostasis to sleep propensity, sleep structure, electroencephalographic slow waves, and sleep spindle activity in humans. J Neurosci 1995; 15:3526-3538.

29. Niedermeyer, Lopes da Silva F. Electroencephalography: basic principles, clinical applications and related fields. Philadelphia: Wilkins \& Wilkins, 1993.

30. Sadato N, Nakamura S, Oohashi T, et al. Neural networks for generation and suppression of alpha rhythm: a PET study. Neuroreport 1998; 9:893-897. 